Check for updates

Cite this: Sustainable Energy Fuels, 2019, 3, 2076

Received 17th January 2019 Accepted 4th June 2019

DOI: $10.1039 / c 9 s e 00030$ e

rsc.li/sustainable-energy

\section{Thermodynamic analysis of high temperature steam and carbon dioxide systems in solid oxide cells $\dagger$}

\begin{abstract}
Petr Vágner, (iD *ab Roman Kodýmª and Karel Bouzek ${ }^{a}$
A thermodynamic analysis of the process in solid oxide cells with $\mathrm{H}_{2} \mathrm{O}$ and $\mathrm{CO}_{2}$ (SOCC) was performed based on the data available in the open literature. This analysis identified a range of operating parameters (temperature and pressure) and the composition of the feed gas mixture ensuring the stability of the system and important reactions with respect to the desired process. Primarily, the thermodynamic equilibrium in the system was determined on the basis of minimizing the Gibbs free energy of the reaction system. Temperature and pressure were the operational parameters studied in the range of $600{ }^{\circ} \mathrm{C}$ to $1000^{\circ} \mathrm{C}$ and 1 bar to 50 bar, respectively. The admissible components in the reaction system were: oxygen, hydrogen, water vapor, carbon dioxide, carbon monoxide, methane, ethane, ethene, formic acid, formaldehyde, methanol and solid carbon (graphitic form). The model predicts the equilibrium mixture composition from which the equilibrium voltage of the cell is computed. The composition of the equilibrium mixture is expressed by means of ternary diagrams as a function of the elemental ratio of carbon, hydrogen and oxygen, known as the $\mathrm{C}: \mathrm{H}: \mathrm{O}$ ratio. The following species appear in negligible amounts in the aforementioned condition ranges in the equilibrium mixture: methanol, formaldehyde, formic acid and oxygen. A strong possibility of solid carbon forming was identified at high conversion of water vapor and carbon dioxide under co-electrolysis conditions. The results of this thermodynamic analysis serve for an evaluation of the degree of conversion with respect to the equilibrium of the outlet gas mixture obtained during the experimental characterization of the solid oxide cell.
\end{abstract}

\section{Introduction}

Solid oxide cells (SOCs) are electrochemical devices - electrolyzers producing fuel, e.g. hydrogen, or fuel cells producing electric current - with a solid oxide ceramic electrolyte operating at temperatures ranging between $600^{\circ} \mathrm{C}$ and $1100{ }^{\circ} \mathrm{C}$. Solid oxide cells represent a promising branch of hydrogen-energy technology, which has been thoroughly investigated in the last few decades. ${ }^{1,2} \mathrm{~A}$ large number of research efforts are presently being dedicated to the investigation of new electrode materials with improved physical characteristics, long-term stability and durability, e.g. see ref. 3-5. The final aim is the development of marketable SOCs. Solid oxide electrolysis cells (SOECs) as well as reversible solid oxide fuel cells (RSOFCs) are still far from technical maturity, in contrast to solid oxide fuel cells (SOFCs). ${ }^{6,7}$ The main challenges to be overcome are connected with system

${ }^{a}$ University of Chemistry and Technology Prague, Technická 5, Prague, Czech Republic. E-mail: petr.vagner@vscht.cz; Fax: +420 220444 410; Tel: +420 220444019

${ }^{b}$ Faculty of Mathematics and Physics, Charles University, Sokolovská 49/83, 18675 Prague, Czech Republic

$\dagger$ Electronic supplementary information (ESI) available. See DOI: 10.1039/c9se00030e durability. Structural degradation is observed in both oxygen and fuel electrodes. Although the percolation of individual phases is crucial, the role of the micro-structure (particularly grain size) of the cell components is still not clear. ${ }^{6}$ On the oxygen side, the production of gas causes delamination of the electrode.

Solid oxide co-electrolysis cells (SOcoECs) represent SOECs with water vapor and carbon dioxide used as reactants, ${ }^{8}$ see

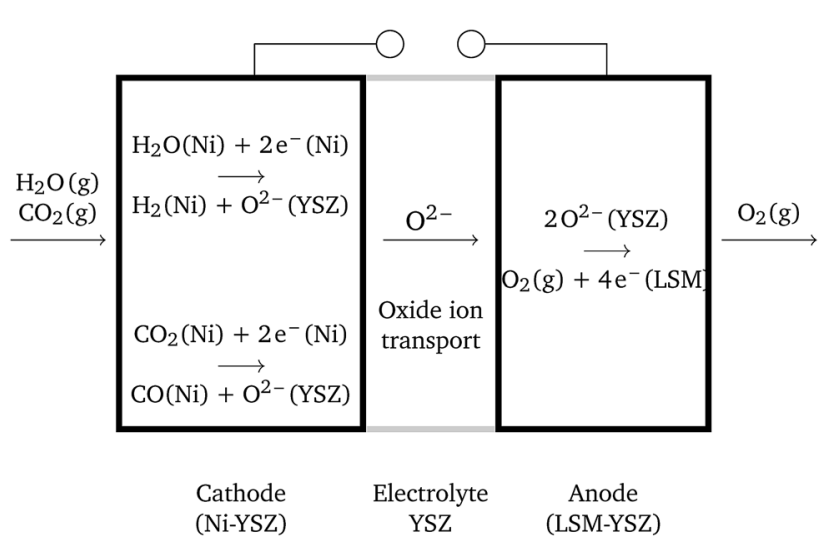

Fig. 1 Scheme of a SOC, when operating as a co-electrolyzer. 
Fig. 1. The carbon dioxide addition to the system leads to the following considerable chemical effects:

- The simultaneous electrolysis of water vapor and carbon dioxide yields a mixture of hydrogen and carbon monoxide syngas, and hence it could serve as a source for subsequent synthesis of methane and other hydrocarbons. ${ }^{9}$

$$
\begin{aligned}
& \mathrm{H}_{2} \mathrm{O} \rightleftharpoons \mathrm{H}_{2}+\frac{1}{2} \mathrm{O}_{2}, \\
& \mathrm{CO}_{2} \rightleftharpoons \mathrm{CO}+\frac{1}{2} \mathrm{O}_{2} .
\end{aligned}
$$

Hence the SOcoEC could be used to reinstate carbon dioxide as a beneficial chemical by way of the power-to-chemicals principle.

- Methane and other hydrocarbons could be produced directly under certain operating conditions. ${ }^{\mathbf{1 0}}$

- Solid carbon soot could appear as an unwanted by-product, forming layers on the electrochemically active surface of the cathode or blocking the electrode pores. ${ }^{11}$

The last point could lead to a considerable reduction of the lifetime of the whole system. It is, therefore, of essential interest to describe and understand this phenomenon. All the abovementioned points are, in principle, valid even if the cell is operated in fuel cell mode. A complex overview and undistorted description of the chemical behavior of the solid oxide cell with a carbon dioxide and water vapor system (SOCc) by means of equilibrium thermodynamics are the subject of this study. The major focus of the study and the literature discussed is devoted to SOcoECs.

\section{Thermodynamic modeling of the SOEC and the SOcoEC}

The development of a detailed model describing the SOC requires employing complex methods, e.g. non-equilibrium thermodynamics. ${ }^{12}$ This study is restricted to a scenario in which the state of the cell (or its part) is, at least temporarily, sufficiently close to equilibrium with its surroundings and, hence, the use of equilibrium thermodynamics (ET), see e.g. ref. 13 , is substantiated. Otherwise a definite thermodynamic state cannot be assigned to the cell as a whole. This can apply not only to the gas at the inlet/outlet of the cell but also to the regions of electrodes where the electron transfer reactions vanish and the reaction equilibrium can occur. In the context of ET, an arbitrary cell exchanges with its surroundings:

- Gaseous species, e.g. $\mathrm{H}_{2}, \mathrm{H}_{2} \mathrm{O}$ and air (inlet and outlet of both electrodes).

- Electric work - electrons, through an external circuit.

- Heat.

This setting allows for the determination of an overall energetic balance and hence for an estimation, for example, of the minimal amount of heat to be removed during an operation in the fuel cell mode, or the heat energy needed for selfsufficient electrolytic operation, $c f$. thermoneutral voltage.
A description of the reactions occurring is more complicated in the case of the SOcoEC. Hence, in order to extend the usual ET machinery, introduced in the following section, the adoption of assumptions regarding the type and extent of electrochemical and chemical reactions is inevitable.

The electrochemical and chemical reactions in the cathode compartment could, in principle, form all kinds of hydrocarbon chemical compounds, depending, in the case of ET, predominantly on temperature, pressure and the $\mathrm{C}: \mathrm{H}: \mathrm{O}$ ratio of the gaseous mixture. Hence, from now on it is assumed that at least $\mathrm{CO}_{2}, \mathrm{CO}, \mathrm{H}_{2} \mathrm{O}$ and $\mathrm{H}_{2}$ are potentially present in the cathode compartment of the co-electrolysis cell. This minimum assumption is common to all literature referenced below, if not specified otherwise.

Consequently, a reaction mechanism needs to be specified. For example, all the admissible chemical and electrochemical reactions could be named in advance, as Broers and Treijtel ${ }^{\mathbf{1 4}}$ did in their early study of carbon deposition in fuel cells. They assumed the presence of gaseous methane and solid carbon in addition to the minimum assumption. They also assumed the occurrence of the water-gas shift reaction,

$$
\mathrm{CO}(\mathrm{g})+\mathrm{H}_{2} \mathrm{O}(\mathrm{g}) \rightleftharpoons \mathrm{CO}_{2}(\mathrm{~g})+\mathrm{H}_{2}(\mathrm{~g})
$$

the methane-steam reforming reaction (4)

$$
\mathrm{CH}_{4}(\mathrm{~g})+\mathrm{H}_{2} \mathrm{O}(\mathrm{g}) \rightleftharpoons 3 \mathrm{H}_{2}(\mathrm{~g})+\mathrm{CO}(\mathrm{g})
$$

and one of the Boudouard reactions

$$
2 \mathrm{CO}(\mathrm{g}) \rightleftharpoons \mathrm{C}(\mathrm{s})+\mathrm{CO}_{2}(\mathrm{~g})
$$

They did not assume any electrochemical reactions.

The other option is to assume that all reactions, respecting mass balances, are admissible, as Sasaki and Teraoka did in ref. 15. They assumed the presence of $c a .300$ gaseous compounds consisting of carbon, hydrogen, oxygen, and solid carbon. They minimized the Gibbs energy for a given $\mathrm{C}: \mathrm{H}: \mathrm{O}$ ratio, temperature and pressure in order to obtain the equilibrium concentrations. The detailed characterization of the $\mathrm{C}: \mathrm{H}: \mathrm{O}$ system equilibria provided in Sasaki and Teraoka's subsequent paper ${ }^{\mathbf{1 6}}$ yielded the composition of the gaseous compounds with solid carbon, and the reversible potential dependency on temperature, pressure and the $\mathrm{C}: \mathrm{H}: \mathrm{O}$ ratio. The reversible potential is evaluated for the air-filled anode at $1000{ }^{\circ} \mathrm{C}$. Apart from this, no further electrochemical considerations were included in this study.

In order to describe the co-electrolysis, an additional model of the electrochemical reactions is necessary. Then an overall energy balance is admissible and, for example, the thermoneutral voltage can be defined.

Assabumrungrat et al. thermodynamically investigated the possibility of carbon formation in a SOC using methanol injection. ${ }^{17}$ They assumed the presence of gaseous methanol and solid carbon over and above the defined minimum assumption. The hydrogen oxidation reaction (1) taking place is the only electrochemical reaction considered by the authors. In 
addition to this, they assumed the occurrence of the methanol decomposition reaction,

$$
\mathrm{CH}_{3} \mathrm{OH}(\mathrm{g}) \rightleftharpoons 2 \mathrm{H}_{2}(\mathrm{~g})+\mathrm{CO}(\mathrm{g})
$$

together with the water gas shift reaction (3). The activity coefficients of carbon in the Boudouard reactions (5) and

$$
\mathrm{CO}(\mathrm{g})+\mathrm{H}_{2}(\mathrm{~g}) \rightleftharpoons \mathrm{C}(\mathrm{s})+\mathrm{H}_{2} \mathrm{O}(\mathrm{g})
$$

served as the detection mechanism of the carbon formation. Calculations of the thermodynamic equilibrium composition were performed by solving a system of non-linear equations relating the moles of each component to the equilibrium constants of the reactions.

Wendel and Pejman $^{18}$ investigated the possibility of reversible solid oxide co-electrolysis cell operation with the assumed presence of $\mathrm{CH}_{4}$. They balanced the enthalpy change due to water vapor reduction (1) (as the only electrochemical step) along with the water gas shift reaction (3) and methanesteam reforming reaction (4). The change of enthalpy is recorded between two "equilibrium" states of the gaseous mixture specified by pressure, temperature, the $\mathrm{C}: \mathrm{H}: \mathrm{O}$ ratio and the amount of removed/added oxygen. Wendel et al.'s incomplete (missing) description of the procedure used to determine the equilibrium states of the gaseous mixtures makes it difficult to deduce whether this procedure allows for compatibility between the initial and the final equilibrium states. This also suggests that the proposed enthalpy balance based on the enthalpy change due to the three assumed reactions may not capture the full extent of the enthalpy change between the initial and the final state. The employed definition of the reversible potential is also disputable, since the reversible potential corresponds to a currentless, equilibrium state. In Wendel et al.'s study, the reversible potential was defined as the rate of change of Gibbs free energy divided by the electric current.

Sun et al. investigated methods of synthetic hydrocarbon fuel production in a pressurized SOcoEC in ref. 10. They assumed methane and solid carbon to be present in the cathode compartment. The scrutinized reaction system contained reactions (1)-(3), the Boudouard reactions (5) and (7), and the carbon monoxide decomposition reaction,

$$
\mathrm{CO}(\mathrm{g}) \rightleftharpoons \mathrm{C}(\mathrm{s})+\frac{1}{2} \mathrm{O}_{2}(\mathrm{~g})
$$

Sun et al. used a purely equilibrium thermodynamics approach. Their definition of the co-electrolysis comprised three stages: initial gas equilibration due to reactions (3) and (4), followed by the co-electrolysis steps (1) and (2) and, finally, equilibration of the resulting mixture with respect to all the non-electrolysis reactions mentioned. Sun et al. proposed a co-electrolysis model where the inlet gaseous mixture in the cathode is first thermodynamically equilibrated, and then water vapor and carbon dioxide are reduced by means of reactions (1) and (2). After the electrolytic reduction, the gaseous mixture is then reequilibrated.
The above analysis of the state-of-the-art shows that, despite the intensive research, the thermodynamic description of the SOC is not satisfactory. The already published research constitutes a useful basis but further discussion is required. The main aims of this work are to support and augment the current knowledge, mainly by clarifying the admissible species and the equilibrium mechanism, together with a discussion of the admissible electrochemical steps and finally by providing a specification of the intended cell operation regime and the surroundings.

\section{Equilibrium model}

The physical reality of solid oxide cells is excruciatingly difficult; therefore, several assumptions defining the physical regime of the described cell are given in the paragraph below. These assumptions frame the scenario where the application of equilibrium thermodynamics is substantiated.

It is assumed that the SOcoEC anode is filled with oxygen at a constant pressure and the cathode, the fuel electrode, is filled with an arbitrary mixture of hydrogen, water vapor, carbon dioxide and carbon monoxide at a constant total pressure.

\subsection{Assumptions}

The whole cell is assumed to be isothermal at a temperature $T$ and a constant pressure $p$ of the gaseous mixture is retained throughout the respective electrodes. The ionically conductive phase, that is, the electrolyte and the parts of the electrodes made of YSZ, is assumed to be an electric insulator. Open circuit conditions, i.e. the circuit connecting the electrodes in Fig. 1 is open, are assumed throughout the paper. Electrochemical potentials of charged species are assumed to be constant within the cell, and for the definition of the electrochemical potential see Subsection 4.2. Finally, the gradients of chemical potentials of gaseous species are assumed to be locally negligible.

\subsection{Corollaries}

First, all electric currents, that is, the fluxes of oxide ions and electrons, are vanishing, although the electrochemical potentials of electrons in the respective electrodes are different.

Secondly, as a consequence, any charged species produced due to an electrochemical reaction are instantly consumed in a parallel electrochemical reaction. For example, if carbon dioxide is being reduced,

$$
\mathrm{CO}_{2}+2 \mathrm{e}^{-} \rightleftharpoons \mathrm{CO}+\mathrm{O}^{2-}
$$

then another reaction, e.g. hydrogen oxidation,

$$
\mathrm{H}_{2}+\mathrm{O}^{2-} \rightleftharpoons \mathrm{H}_{2} \mathrm{O}+2 \mathrm{e}^{-} \text {, }
$$

needs to proceed in the opposite direction so that any excess charge is consumed and constant electrochemical potentials are maintained. Summing the two reactions gives the water-gas shift reaction (3). 
Ultimately, only chemical reactions of neutral species require being accounted for.

Macroscopically, the gaseous mixture in the electrode undergoes chemical reactions. The assumption of vanishing chemical potentials of the gaseous species could be interpreted in at least, two ways: either the electrode is not in contact with the mixture and the chemical equilibrium is attained or the gaseous mixture flows through the electrode in a way that the diffusion could be neglected and the gas is in a local chemical equilibrium.

The above outlined reduction of the cell dynamics to a level of equilibrium thermodynamics could be viewed as the separation of three different time scales: relaxation of charged species, relaxation of electrochemical reactions and relaxation of chemical reactions. The mode of transport of gaseous species is assumed so that it can be neglected.

As a consequence, the use of equilibrium thermodynamics is justified.

\subsection{Model description}

The following process is modeled: a mixture of $N$ gaseous species with a given initial molar composition $\mathbf{n}_{\mathrm{g}}^{\text {init }}=\left(n_{1}^{\text {init }}, \ldots, n_{N}^{\text {init }}\right)$ is in contact with solid carbon $n_{C}^{\text {init }}$ and this mixture is kept under constant pressure $p$ and temperature $T$ until the mixture reaches the equilibrium composition $\mathbf{n}^{\mathrm{eq}}=\left(\mathbf{n}_{\mathrm{g}}^{\mathrm{eq}}, n_{C}^{\mathrm{eq}}\right)$ given by the Gibbs energy minimum of the mixture.

The Gibbs energy of such a mixture can be written as

$$
G\left(p, T, \mathbf{n}_{\mathrm{g}}, n_{C}\right)=\sum_{\alpha=1}^{N} n_{\alpha} \mu_{\alpha}\left(p, T, \mathbf{n}_{\mathrm{g}}, n_{C}\right)+n_{C} \mu_{C}\left(p, T, \mathbf{n}_{\mathrm{g}}, n_{C}\right)
$$

provided that

$$
\mu_{\alpha}\left(p, T, \mathbf{n}_{\mathrm{g}}, n_{C}\right)=\left(\frac{\partial G}{\partial n_{\alpha}}\right)_{p, T, n_{\beta \neq \alpha}}, \quad \alpha, \beta \in\{1, \ldots, N, C\} .
$$

The symbol $n_{\alpha}$ stands for the number of moles of species $\alpha$ and $\mu_{\alpha}$ denotes the chemical potential of species $\alpha$.

3.3.1 Ideal mixture of ideal gases. The gaseous mixture in contact with the cathode is assumed to behave as an ideal mixture of ideal gases. According to Wendel $^{18}$ and Todd, ${ }^{19}$ it provides a sufficient approximation for temperatures around $800{ }^{\circ} \mathrm{C}$ and pressures less than 100 bar. Hence, this gives

$$
\mu_{\alpha}\left(T, p_{\alpha}\right)=\mu_{\alpha}\left(T, p^{\mathrm{st}}\right)+R T \log \left(\frac{p_{\alpha}}{p^{\mathrm{st}}}\right) \quad \alpha \in\{1, \ldots, N\},
$$

where $p^{\text {st }}=100 \mathrm{kPa}$ is the standard pressure, $p_{\alpha}$ the partial pressure, and the symbol $\mu_{\alpha}\left(T, p^{\text {st }}\right)$ stands for the standard molar chemical potential of the pure substance.

Solid carbon is assumed, besides the chemical reactions, not to interact with the gaseous mixture. Hence, the carbon chemical potential does not depend on the pressure and the mixture composition. Conversely, the chemical potentials of gases do not depend on the moles of the carbon atoms. This means that $\mu_{C}(T)$ only depends on the temperature. Thus the influence of the boundary between the gaseous phase and solid carbon is neglected and the model cannot, in principle, capture the
Table 1 Admissible compounds and phases. The last three columns constitute the matrix $M$. The thermodynamic data for all compounds except formaldehyde were taken from ref. 22. The thermodynamic data for formaldehyde were sourced from ref. 23

\begin{tabular}{lllll}
\hline Compound & Phase & $\# \mathrm{C}$ & $\# \mathrm{H}$ & $\# \mathrm{O}$ \\
\hline Molecular hydrogen $\mathrm{H}_{2}$ & $\mathrm{G}$ & 0 & 2 & 0 \\
Molecular oxygen $\mathrm{O}_{2}$ & $\mathrm{G}$ & 0 & 0 & 2 \\
Water vapor $\mathrm{H}_{2} \mathrm{O}$ & $\mathrm{G}$ & 0 & 2 & 1 \\
Carbon dioxide $\mathrm{CO}_{2}$ & $\mathrm{G}$ & 1 & 0 & 2 \\
Carbon monoxide CO & $\mathrm{G}$ & 1 & 0 & 1 \\
Methane $\mathrm{CH}_{4}$ & $\mathrm{G}$ & 1 & 4 & 0 \\
Formic acid $\mathrm{HCOOH}$ & $\mathrm{G}$ & 1 & 2 & 2 \\
Formaldehyde $\mathrm{CH}_{2} \mathrm{O}$ & $\mathrm{G}$ & 1 & 2 & 1 \\
Methanol $\mathrm{CH}_{3} \mathrm{OH}$ & $\mathrm{G}$ & 1 & 4 & 1 \\
Ethane $\mathrm{C}_{2} \mathrm{H}_{6}$ & $\mathrm{G}$ & 2 & 6 & 0 \\
Ethene $\mathrm{C}_{2} \mathrm{H}_{4}$ & $\mathrm{G}$ & 2 & 4 & 0 \\
Carbon $\mathrm{C}$ (graphite) & $\mathrm{S}$ & 1 & 0 & 0 \\
& & & &
\end{tabular}

complicated reality of carbon formation in a real SOC cathode, where the geometry of carbon soot whiskers t and different carbon forms, see ref. 20 and 21, should be taken into account. The finally employed form of the Gibbs energy reads as

$$
G\left(p, T, n_{\mathrm{g}}, n_{C}\right)=\sum_{\alpha=1}^{N} n_{\alpha}\left(\mu_{\alpha}^{\mathrm{st}}(T)+R T \log \frac{p_{\alpha}}{p^{\mathrm{st}}}\right)+n_{C} \mu_{C}^{\mathrm{st}}(T) .
$$

3.3.2 Gaseous mixture and thermodynamic data. The assumed gaseous species appearing in the cathode are summarized in Table 1.

3.3.3 Chemical reactions and mass conservation. Chemical reactions occurring in the cathode transform $\left(\mathbf{n}_{\mathrm{g}}^{\text {init }}, n_{C}^{\text {init }}\right)$ into $\left(\mathbf{n}_{\mathrm{g}}^{\mathrm{eq}}, n_{C}^{\mathrm{eq}}\right)$ so that the mass is conserved. $\S$ The Gibbs energy, see eqn (14), is minimized with respect to the moles of the admissible species $\left(\mathbf{n}_{\mathrm{g}}, n_{C}\right)$, thus keeping the number of moles of atoms of the respective elements constant. The species listed in Table 1 are composed of hydrogen, oxygen and carbon atoms. The element vector is defined as

$$
\mathbf{a}:=\left(a_{C}, a_{\mathrm{H}}, a_{\mathrm{O}}\right)=\mathbf{M}\left(\mathbf{n}_{\mathrm{g}}^{\text {init }}, n_{C}^{\text {init }}\right)^{T},
$$

The element matrix $\mathbf{M}$ is defined according to Table 1 . The element vector a contains information about the amount of elements in the cathode and, due to the conservation of mass, remains constant during the minimization of $G$.

3.3.4 Numerical solution of minimization. The minimization was implemented in MATLAB using fmincon with an interior-point algorithm. The results were partially validated by using ASPEN and Chemical Equilibrium with Applications of NASA. $^{23}$ Slight differences between the results of these two modeling tools and the presented model are due to a slight variation in the feed thermodynamic data.

† Thin, intertwined, graphite fibers.

$\S$ The reactions change the moles $n^{\text {init }}$ into $n^{\mathrm{eq}}$, i.e., the reactions act on the quantity. 


\section{Results}

The equilibrium composition of the mixture predicted by the model depends only on the $\mathrm{C}: \mathrm{H}: \mathrm{O}$ ratio, which is normalized element vector a, see eqn (15), temperature and pressure, but not on the particular mixture composition. It is, therefore, advantageous to render the minimization results in the form of ternary diagrams, see Fig. 2.

The value of the $\mathrm{C}: \mathrm{H}: \mathrm{O}$ ratio is not the sole factor determining the composition of the mixture. In order to illustrate the relationship between the ternary diagram and co-electrolysis, for the remainder of this paragraph only mixtures usually used for co-electrolysis are assumed: mixtures of water vapor, carbon dioxide and hydrogen. The mixtures listed below are not necessarily in equilibrium. The $\mathrm{C}: \mathrm{H}: \mathrm{O}$ ratios corresponding to mixtures of $\mathrm{H}_{2} \mathrm{O}$ with $\mathrm{CO}_{2}$, and of $\mathrm{H}_{2}$ with $\mathrm{CO}$ are denoted by solid black line segments in Fig. 2. The region delimited by solid black lines in Fig. 2 represents the $\mathrm{C}: \mathrm{H}: \mathrm{O}$ ratios of all mixtures of $\mathrm{H}_{2}, \mathrm{H}_{2} \mathrm{O}$, $\mathrm{CO}$ and $\mathrm{CO}_{2}$ and is referred to as the coelectrolysis region in the rest of the article. In particular, the black dotted line segments denote the $\mathrm{C}: \mathrm{H}: \mathrm{O}$ ratios corresponding to the mixtures of $\mathrm{H}_{2}$ with $\mathrm{CO}_{2}$, and of $\mathrm{H}_{2} \mathrm{O}$ with $\mathrm{CO}$, respectively.

Note the particular mixture of $\mathrm{CO}_{2}$ and $\mathrm{H}_{2} \mathrm{O}$ and the corresponding $\mathrm{C}: \mathrm{H}: \mathrm{O}$ ratio in Fig. 2. If all carbon dioxide in such

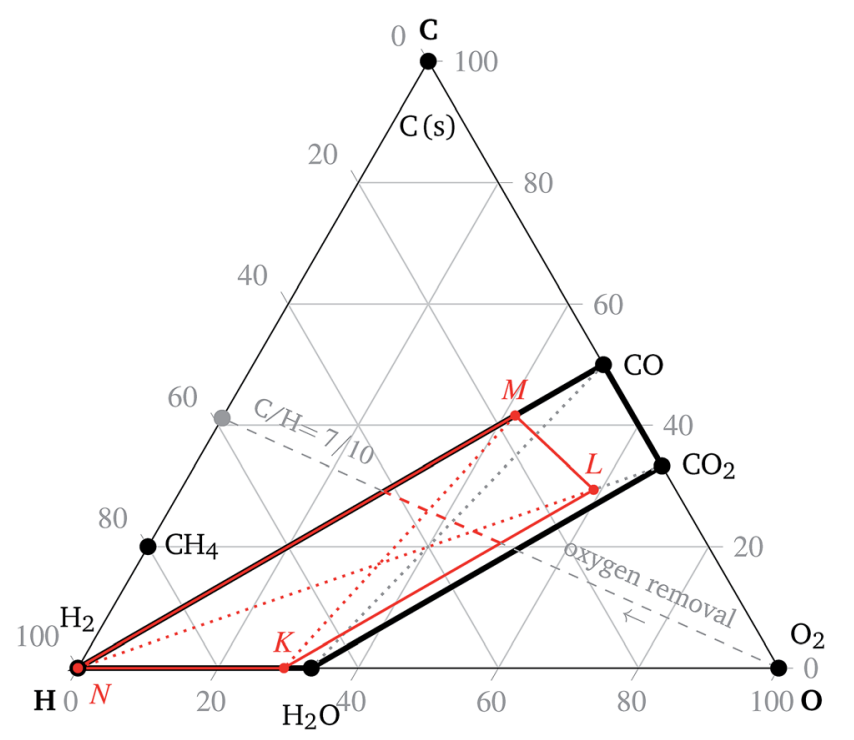

Fig. 2 Ternary diagram defining limiting compositions and the process of oxygen removal for the SOcoEC process. The co-electrolysis region is given by the vertices of $\mathrm{H}_{2}, \mathrm{H}_{2} \mathrm{O}, \mathrm{CO}_{2}$ and $\mathrm{CO}$ and denoted by a solid black line. The region contains all possible $\mathrm{C}: \mathrm{H}: \mathrm{O}$ ratios of mixtures of the four aforementioned compounds. The line segment between $\mathrm{H}_{2} \mathrm{O}$ and $\mathrm{CO}_{2}$ represents $\mathrm{C}: \mathrm{H}$ : O ratios of mixtures before the co-electrolysis, where hydrogen and carbon are both fully oxidized. The diagonals of the electrolysis trapezoid, marked by gray dotted lines, represent $\mathrm{C}: \mathrm{H}: \mathrm{O}$ ratios corresponding to the various mixtures of $\mathrm{H}_{2} \mathrm{O}$ with $\mathrm{CO}$ and $\mathrm{H}_{2}$ with $\mathrm{CO}_{2}$, prior to the approach of the mixture to equilibrium. The slope of the oxygen removal lines-electrolysis lines-becomes steeper with the rising portion of water vapor in the initial mixture, $c f$. the slope of $\overline{\mathrm{LM}}$ and $\overline{\mathrm{KN}}$. a mixture is replaced by carbon monoxide, e.g. via the reduction reaction (9), the new resulting mixture will lie on the intersection of the line segment connecting $\mathrm{CO}$ and $\mathrm{H}_{2} \mathrm{O}$ and the oxygen removal line with the corresponding $\mathrm{C} / \mathrm{H}$ ratio. Conversely, if all water vapor is replaced by hydrogen, e.g. via the reduction reaction (10), then the resulting $\mathrm{C}: \mathrm{H}: \mathrm{O}$ ratio will lie on the intersection of the line segment connecting $\mathrm{H}_{2}$ and $\mathrm{CO}_{2}$ and the corresponding oxygen removal line. If both $\mathrm{H}_{2} \mathrm{O}$ and $\mathrm{CO}_{2}$ are replaced by $\mathrm{H}_{2}$ and $\mathrm{CO}$, respectively, the resulting $\mathrm{C}: \mathrm{H}: \mathrm{O}$ ratio will be given by the intersection of the line segment connecting $\mathrm{H}_{2}$ and $\mathrm{CO}$ with the corresponding oxygen removal line. In principle, the process of co-electrolysis removes oxygen from the gaseous mixture, whilst the ratio of atomic carbon and hydrogen remains constant. Such points are represented by line segments beginning at point $\mathrm{O}_{2}$. The action of the electrochemical steps (9) and (10) cannot be distinguished in the ternary diagram. The trapezoid $\overline{\mathrm{KLMN}}$, marked by the red solid lines in Fig. 2, represents all possible mixtures of $\mathrm{H}_{2}, \mathrm{H}_{2} \mathrm{O}, \mathrm{CO}_{2}$ and CO, supplemented by $20 \%$ hydrogen gas, which might be the case in applications.

The co-electrolysis region in the ternary diagram is defined as the trapezoid given by vertices corresponding to $\mathrm{H}_{2} \mathrm{O}, \mathrm{CO}_{2}$, $\mathrm{CO}$ and $\mathrm{H}_{2}$, see Fig. 2 and the oxidation region as the triangle given by vertices corresponding to $\mathrm{O}_{2}, \mathrm{H}_{2} \mathrm{O}$ and $\mathrm{CO}_{2}$, see Fig. 2 .

\subsection{Temperature and pressure effects on equilibrium composition}

A total of 11 species and oxygen, see Table 1, were admitted to be potentially present in the equilibrated gaseous mixture in the cathode compartment. The conditions investigated ranged from $600{ }^{\circ} \mathrm{C}$ to $1000{ }^{\circ} \mathrm{C}$ and from 1 bar to $50 \mathrm{bar}$. The following species do not appear in these condition ranges in the equilibrium: methanol, formaldehyde, formic acid, ethane, ethene and oxygen. This finding is in agreement with Sasaki's results. ${ }^{\mathbf{1 6}}$ The main trends of mixture behavior are described in the following paragraphs. The ternary diagrams of $\mathrm{H}_{2} \mathrm{O}$ and additional ternary diagrams of $\mathrm{CO}$ and $\mathrm{CH}_{4}$ are presented in the ESI. $\dagger$

4.1.1 Hydrogen and water vapor. The ternary diagrams showing the equilibrium relative partial pressure of hydrogen are shown in Fig. 3a-c and $4 a-c$. Hydrogen atoms in equilibrium are distributed between gaseous hydrogen, water vapor and methane. The presence of a sufficient amount of oxygen enables total hydrogen oxidation, which is delimited by the oxidation region, see triangle $\mathrm{H}_{2} \mathrm{O}, \mathrm{O}_{2}$ and $\mathrm{CO}_{2}$ in Fig. 2. Outside this oxidation region hydrogen reacts favourably with water vapor and methane, see Fig. 5, via reaction (4) at lower temperatures. There is competition between the water gas shift reaction (3) and the Boudouard reactions (7) and (5). Hence, carbon monoxide, see Fig. 6, and solid carbon are formed at higher temperatures.

4.1.2 Carbon dioxide and carbon monoxide. The equilibrium molar fractions of carbon dioxide are plotted in the right hand side column of Fig. $3 \mathrm{~d}-\mathrm{f}$ and $4 \mathrm{~d}-\mathrm{f}$. The ratio between carbon dioxide and carbon monoxide follows the situation discussed in the previous paragraph: if hydrogen is fully 


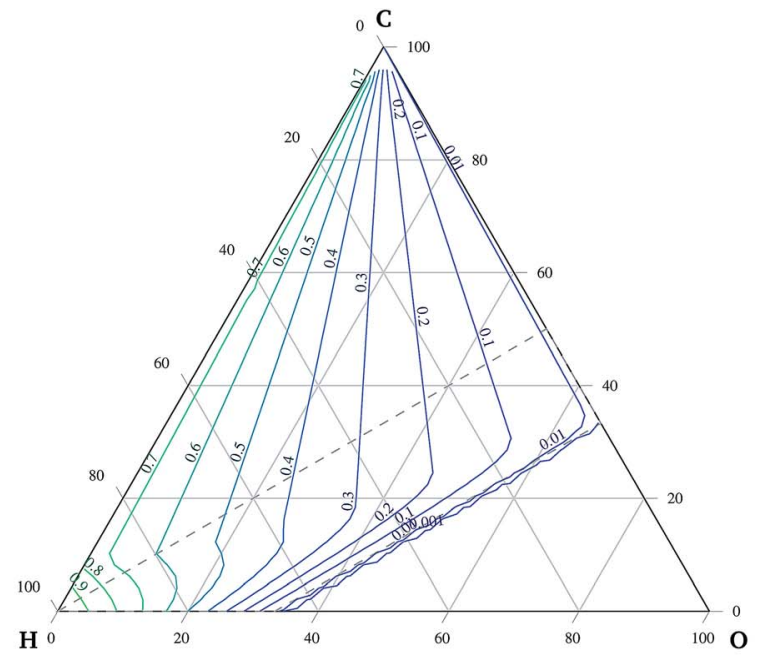

(a) Relative partial pressure of $\mathrm{H}_{2}$ at $600^{\circ} \mathrm{C}$ and 1 bar

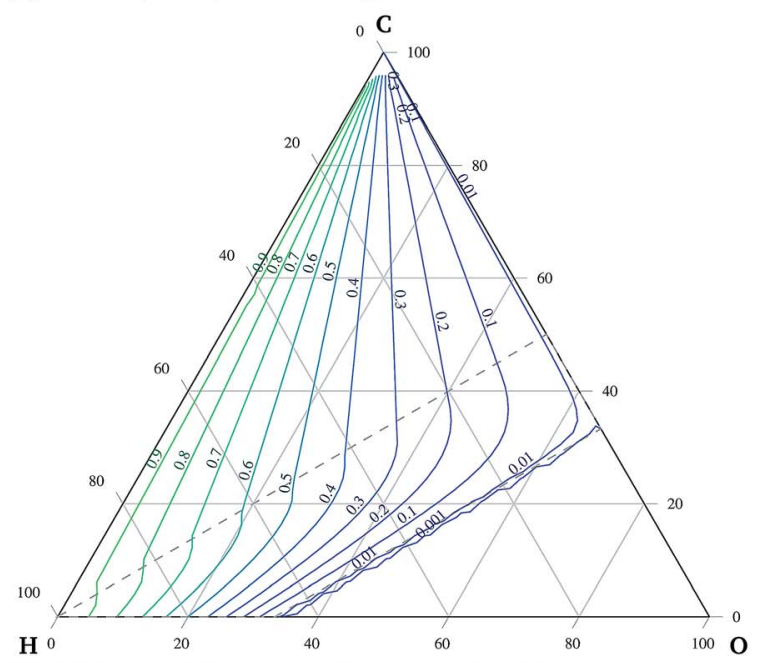

(b) Relative partial pressure of $\mathrm{H}_{2}$ at $800^{\circ} \mathrm{C}$ and 1 bar

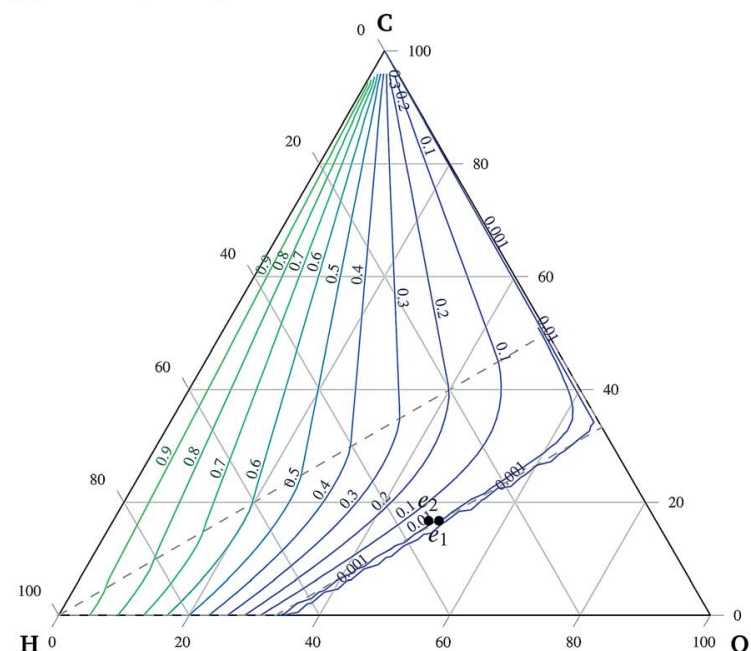

(c) Relative partial pressure of $\mathrm{H}_{2}$ at $1000^{\circ} \mathrm{C}$ and 1 bar

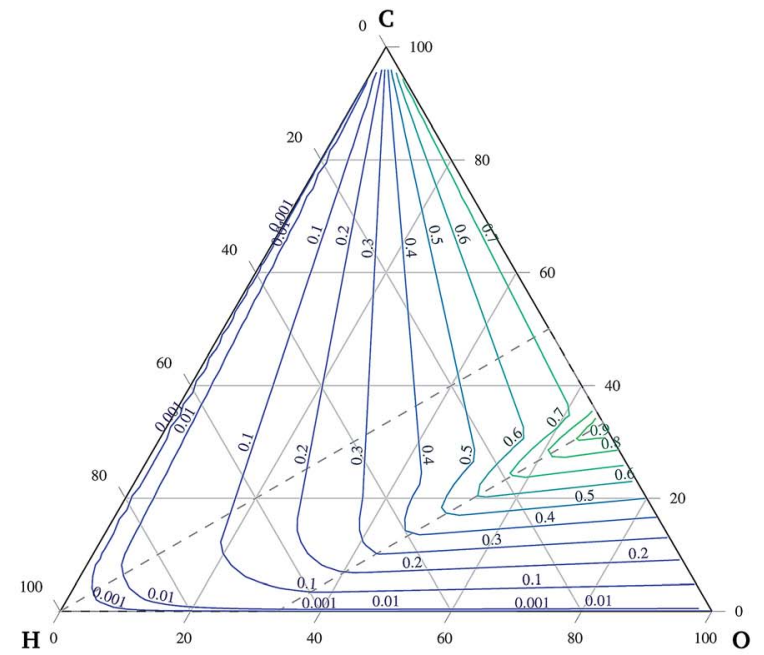

(d) Relative partial pressure of $\mathrm{CO}_{2}$ at $600^{\circ} \mathrm{C}$ and 1 bar

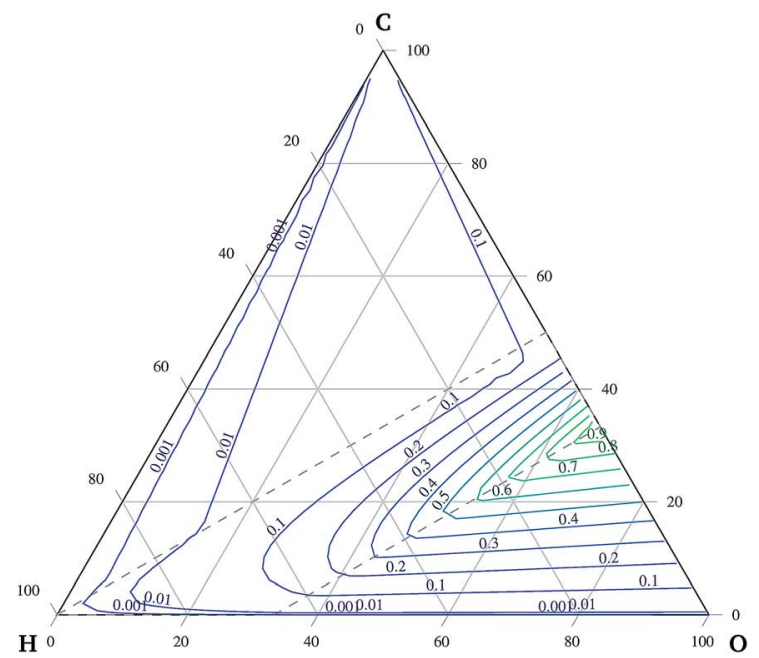

(e) Relative partial pressure of $\mathrm{CO}_{2}$ at $800^{\circ} \mathrm{C}$ and 1 bar

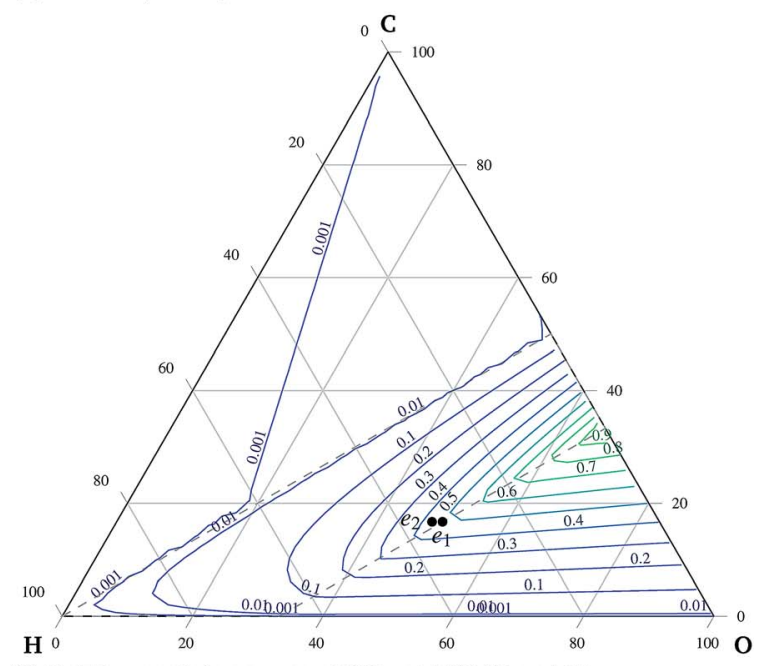

(f) Relative partial pressure of $\mathrm{CO}_{2}$ at $1000^{\circ} \mathrm{C}$ and $1 \mathrm{bar}$

Fig. 3 Relative partial pressures of $\mathrm{H}_{2}$ (a to $\mathrm{c}$ ) and $\mathrm{CO}_{2}$ (d to f) at 1 bar.

oxidized, meaning that the $\mathrm{C}: \mathrm{H}: \mathrm{O}$ ratio is in the oxidation region, carbon is present exclusively in the form of carbon dioxide. An important observation is the preference of carbon monoxide over carbon dioxide at high temperatures outside the oxidation region, which means that carbon monoxide is stable if formed there. Therefore, carbon monoxide will remain in the 


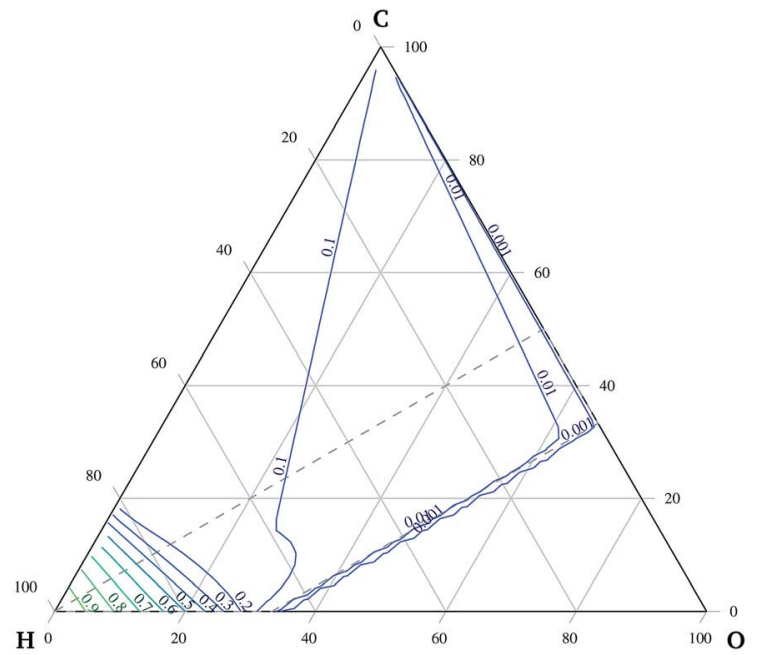

(a) Relative partial pressure of $\mathrm{H}_{2}$ at $600^{\circ} \mathrm{C}$ and 50 bar

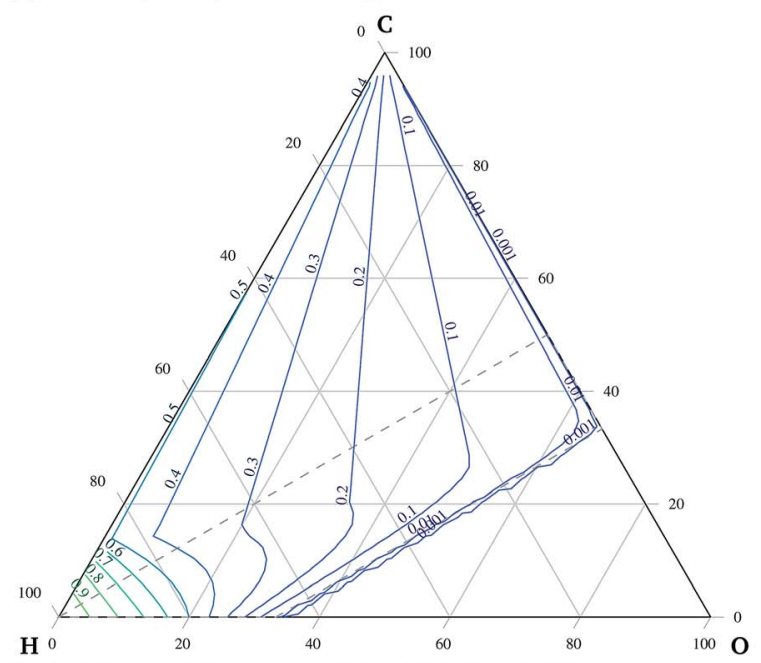

(b) Relative partial pressure of $\mathrm{H}_{2}$ at $800^{\circ} \mathrm{C}$ and $50 \mathrm{bar}$

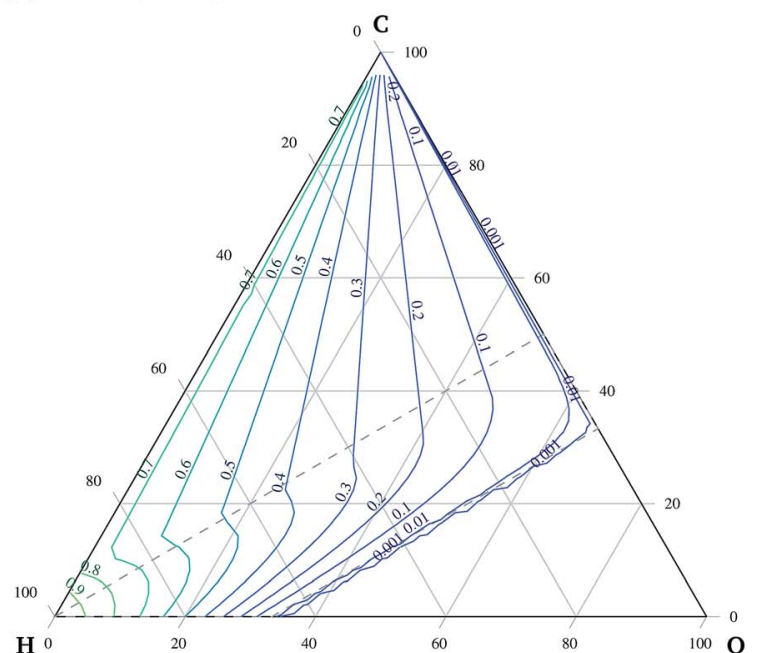

(c) Relative partial pressure of $\mathrm{H}_{2}$ at $1000{ }^{\circ} \mathrm{C}$ and $50 \mathrm{bar}$

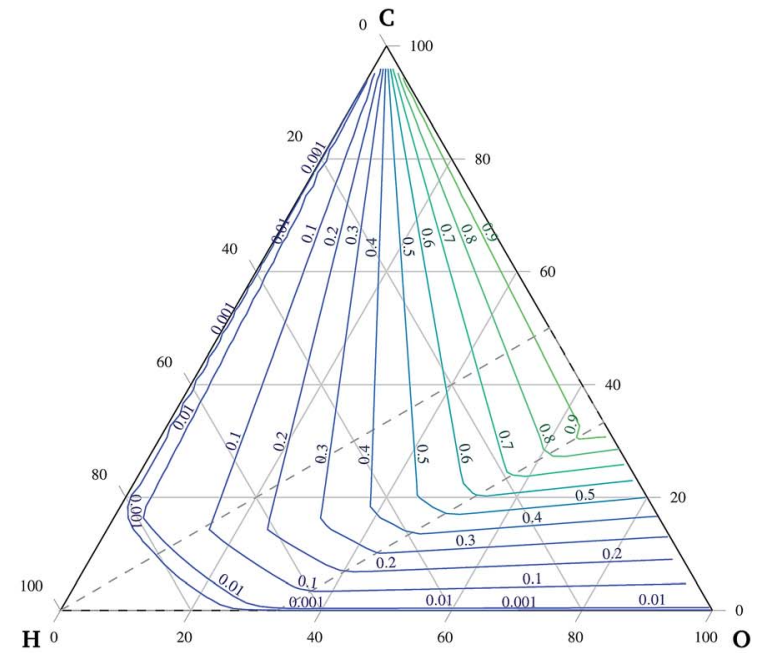

(d) Relative partial pressure of $\mathrm{CO}_{2}$ at $600^{\circ} \mathrm{C}$ and $50 \mathrm{bar}$

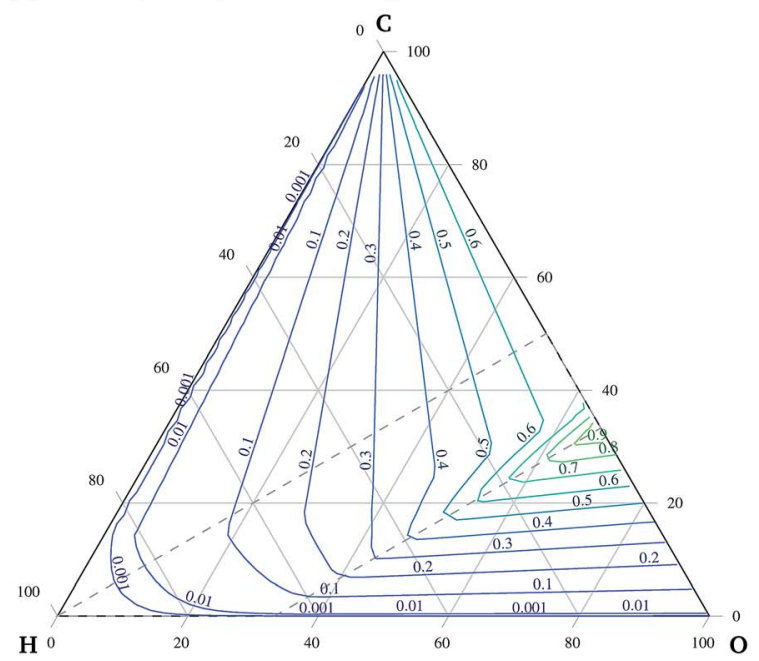

(e) Relative partial pressure of $\mathrm{CO}_{2}$ at $800^{\circ} \mathrm{C}$ and $50 \mathrm{bar}$

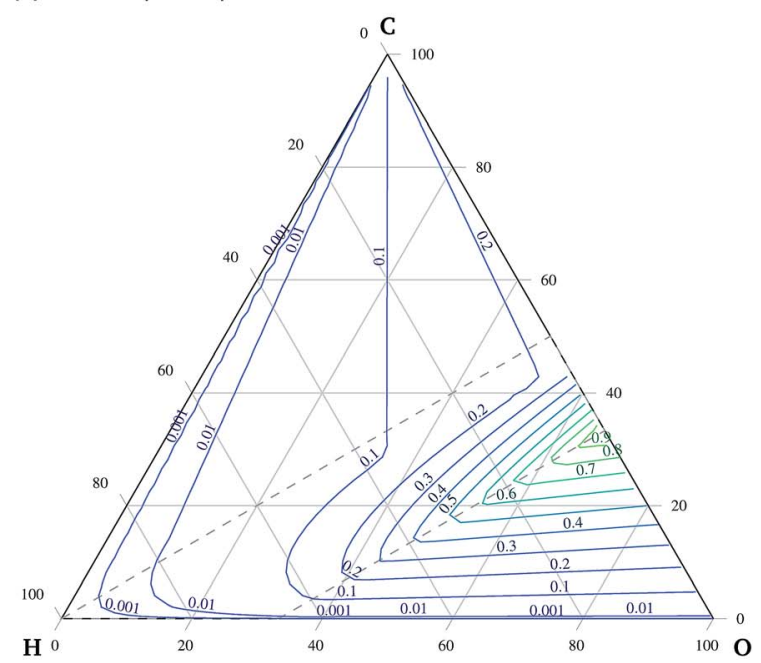

(f) Relative partial pressure of $\mathrm{CO}_{2}$ at $1000{ }^{\circ} \mathrm{C}$ and $50 \mathrm{bar}$

Fig. 4 Relative partial pressures of $\mathrm{H}_{2}$ (a to $\mathrm{c}$ ) and $\mathrm{CO}_{2}$ (d to f) at 50 bar.

gaseous mixture once formed during co-electrolysis, see Fig. 6. This is mainly the case at higher temperatures and atmospheric pressure due to the effects of reaction (3).
Torrell et $a .^{24}$ observed continuous conversion of a $\mathrm{H}_{2} \mathrm{O}: \mathrm{CO}_{2}=1: 1$ mixture into approximately $\mathrm{H}_{2} \mathrm{O}: \mathrm{CO}_{2}: \mathrm{H}_{2}: \mathrm{CO}$ $=22: 22: 2: 1$ during co-electrolysis in a symmetric cell with 


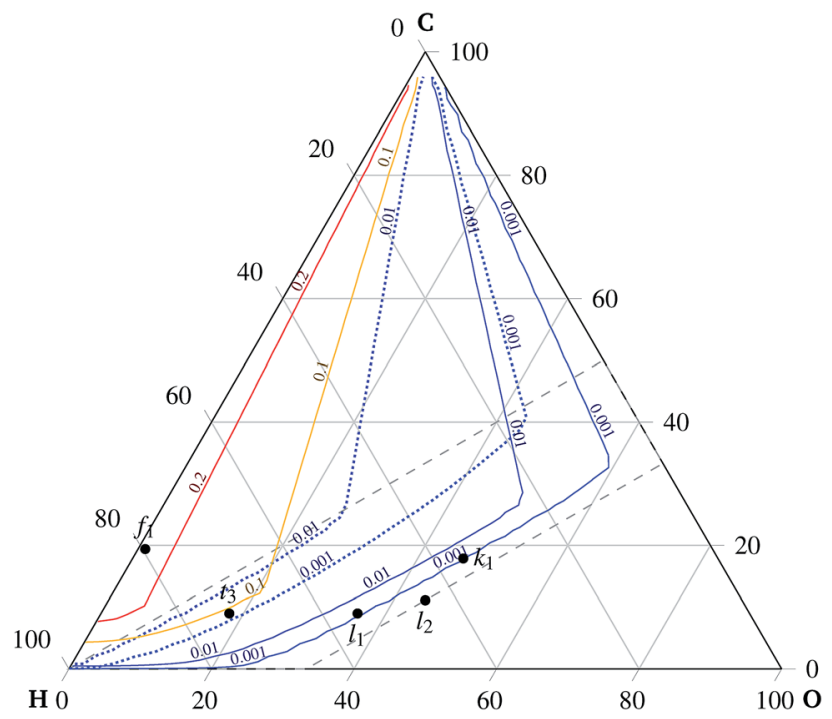

Fig. 5 Partial pressure of $\mathrm{CH}_{4}$ in the gaseous mixture at 1 bar. Dotted lines denote $800{ }^{\circ} \mathrm{C}$ and solid lines $600{ }^{\circ} \mathrm{C}$.

a LaSrCrMnO electrode at $900{ }^{\circ} \mathrm{C}$ while the applied current density was $150 \mathrm{~A} \mathrm{~cm}^{-2}$. The initial and the final composition are denoted as $e_{1}$ and $e_{2}$, respectively, in Fig. $3 \mathrm{c}$ and $\mathrm{f}$. The existence of $\mathrm{H}_{2}$ is clearly favored for the final composition of the mixture as predicted by the model. 9

4.1.3 Carbon deposition. The regions with the presence of solid carbon are shown in Fig. 7. The intersection of regions with a substantial presence of solid carbon with the coelectrolysis region, $c f$. Fig. 2 and 7 , is non-trivial at lower temperatures or higher pressures. If solid carbon is formed during the co-electrolysis, a $\mathrm{H}_{2}$ supplement will improve its stability. Increased pressure lowers the stability of carbon for mixtures with a higher water vapor (and hydrogen) content even for higher co-electrolysis conversion (i.e. greater removal of $\mathrm{O}$ ), whilst it increases the possibility of carbon formation elsewhere. Increasing temperature decreases the intersection of the carbon stable region and the co-electrolysis region, see Fig. 7.

Experimental observations of solid carbon formation confirming the presented results were reported in ref. 25-30. First, the mixtures of carbon dioxide and carbon monoxide (no hydrogen) were prone to carbon deposition as shown in ref. 25 for a 1 : 1 mixture at $700{ }^{\circ} \mathrm{C}$ discharging at $0.7 \mathrm{~V}$. Direct methane decomposition led to carbon deposition onto an electrode in ref. 26 under $\mathrm{OCV}$ conditions at $1000^{\circ} \mathrm{C}$. Electrolysis of mixtures with a higher $\mathrm{C} / \mathrm{H}$ ratio was also reportedly a source of electrode carbonization as in ref. 27. Mixtures of $\mathrm{H}_{2}$ and CO, i.e. points $a_{2}$, $a_{3}$, and $a_{4}$ indicated in Fig. 7, were studied under open circuit and mild anodic polarization $\left(10 \mathrm{~mA} \mathrm{~cm}{ }^{-2}\right)$ conditions. Both regimes revealed the highest share of deposited carbon for a $1: 3$ ratio of $\mathrm{H}_{2}$ to $\mathrm{CO}$, see point $a_{4}$ in Fig. 7 , decreasing with increasing concentration of hydrogen. The amount of deposited carbon was slightly lower for the polarized case. A considerable carbon deposition under OCV conditions is observed for pure

I The ternary diagrams of CO are contained in the ESI.
$\mathrm{CO}$ in ref. 27 at $800{ }^{\circ} \mathrm{C}$ and in ref. 30 for a mixture of $0.004 \% \mathrm{CO}$ and $99.996 \% \mathrm{~N}_{2}$ at $600{ }^{\circ} \mathrm{C}$, whereas there is no carbon deposition at $700{ }^{\circ} \mathrm{C}$.

An extensive carbon deposition under OCV conditions is observed in ref. 29 for both dry $\mathrm{CH}_{4}$ and a mixture of $\mathrm{CH}_{4}: \mathrm{H}_{2} \mathrm{O}=$ $19.3: 1$ at $600{ }^{\circ} \mathrm{C}$ for a Ni-YSZ porous electrode, see Fig. 7 point $f_{1}$. The deposition is diminished, though not eliminated, by $1 \mathrm{wt} . \%$ Mo doping.

No carbon deposition is reported for pure carbon monoxide inlet gas under mild anodic polarization at $800{ }^{\circ} \mathrm{C}$ for $50 \mathrm{~mA}$ $\mathrm{cm}^{-2}$ in ref. 25 and $10 \mathrm{~mA} \mathrm{~cm}{ }^{-2}$ in ref. 27 . Although the model predicts carbon deposition for pure carbon monoxide, see point $a_{1}$ in Fig. 7, the mild polarization could lead to nonequilibrium conditions. Experimental evidence suggests that the kinetics of the carbon monoxide disproportionation reaction (5) on a nickel surface is slower than the rate of the carbon monoxide reduction reaction (7), as reported in ref. 27 . The kinetic constant of reaction (5) is reportedly ten times smaller than the kinetic constant of reaction (7). Hence, the equilibrium might not have been attained in this case. The presented thermodynamics model fails to replicate the observed carbon deposition reported in ref. 26, studied under conditions of steam reforming of $\mathrm{C}_{2} \mathrm{H}_{6}$ and $\mathrm{C}_{2} \mathrm{H}_{4}$, indicated by points $t_{1}$ and $t_{2}$ in Fig. 7, respectively. Moreover the experimental work $^{26}$ reports different behaviors of the solid carbon phase for different alkali metal dopings. Therefore, this points to the conclusion that the thermodynamic equilibrium might not have been attained in this case either.

All the presented experimental studies were performed with an atmospheric pressure with occasional introduction of an inert gas.

4.1.4 Methane. The stable presence of methane in the mixture is observed at lower temperatures, see Fig. 5, due to the domination of reaction (4). The presence of methane is not favored at a high temperature even though it can be partially enhanced by a pressure increase.

The formation of stable methane during electrolysis of the mixture of $\mathrm{CO}_{2}, \mathrm{H}_{2} \mathrm{O}$, and $\mathrm{H}_{2}$ at $650{ }^{\circ} \mathrm{C}$ under open circuit conditions, see point $l_{1}$ indicated in Fig. 5 , is in agreement with the model prediction reported in ref. 31. The assessment of quantitative agreement is not possible due to certain discrepancies in ref. 31. Moreover, no methane is detected in ref. 31 for the mixture of the same type indicated by point $l_{2}$ in Fig. 5 , which also agrees with the model prediction. In accordance with the prediction, the findings presented in ref. 32 show negligible methane formation during co-electrolysis of $\mathrm{a}_{2} \mathrm{O}-$ $\mathrm{CO}_{2}$-rich mixture with $\mathrm{H}_{2}$ and $\mathrm{CO}$ at temperatures around $800{ }^{\circ} \mathrm{C}$ and $1.8 \mathrm{~V}$, using helium as an inert gas halving the effective partial pressure of the active components, see point $k_{1}$ in Fig. 5. The temperature-increasing conversion of steamreformed methane reported in ref. 26 agrees with the trend of methane stability shown by the modeling results. The reported methane conversion is more than $99 \%$ at $800{ }^{\circ} \mathrm{C}$, see point $t_{3}$ indicated in Fig. 5.

The stable presence of methane is observed by Finnerty et al. ${ }^{29}$ for both dry $\mathrm{CH}_{4}$ and a mixture of $\mathrm{CH}_{4}: \mathrm{H}_{2} \mathrm{O}=19.3: 1$ at $600{ }^{\circ} \mathrm{C}$, see Fig. 5 point $f_{1}$. This is in agreement with the model 


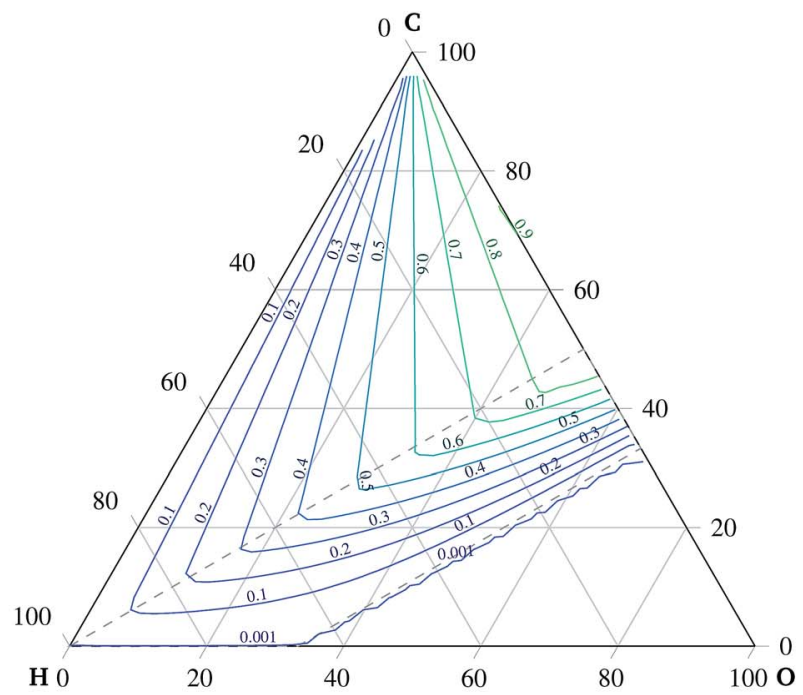

(a) Relative partial pressure of $\mathrm{CO}$ at $800^{\circ} \mathrm{C}$ and 1 bar

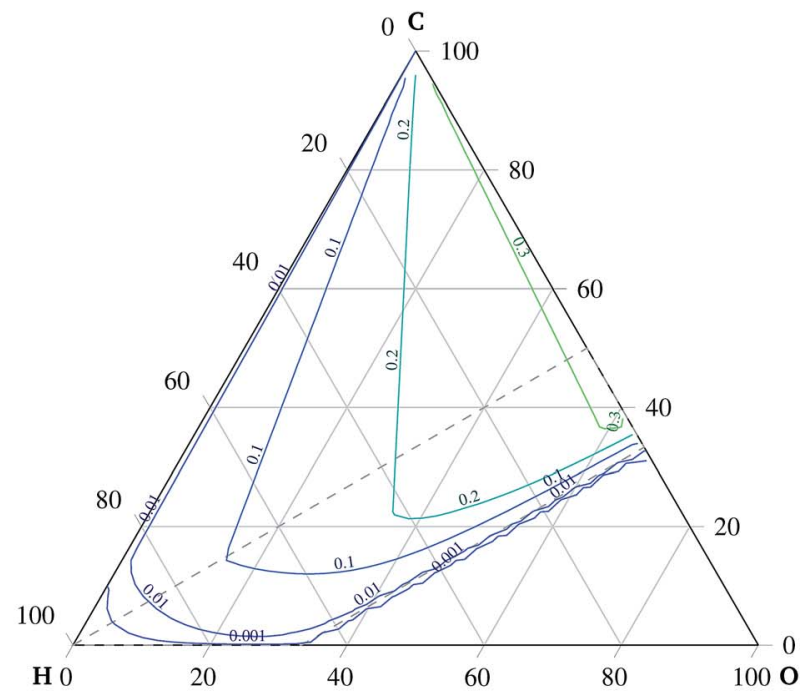

(b) Relative partial pressure of $\mathrm{CO}$ at $800{ }^{\circ} \mathrm{C}$ and $50 \mathrm{bar}$

Fig. 6 Comparison of relative partial pressures of $\mathrm{CO}$ at (a) 1 bar and (b) 50 bar.

prediction. They report greater selectivity towards $\mathrm{CO}$ in the case of humidified $\mathrm{CH}_{4}$.

\subsection{Open circuit potential}

The mixture is assumed to be in equilibrium, and hence the overall rates of all chemical and electrochemical reactions vanish. This is equivalent to the vanishing electrochemical affinities of the respective reactions. The electrochemical potential of a charged species is defined as

$$
\tilde{\mu}=\mu+z F \varphi
$$

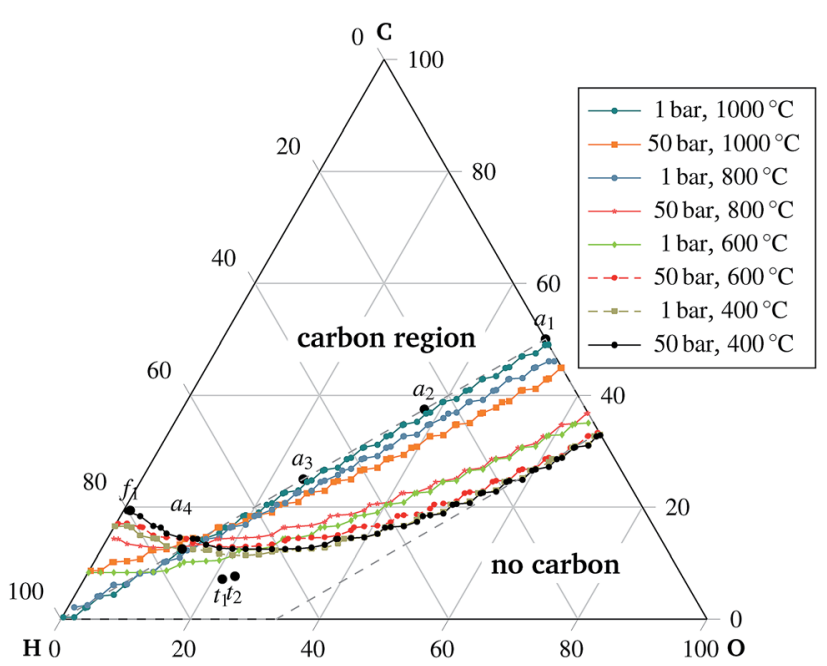

Fig. 7 Carbon deposition. The curves indicate, for the given temperature and pressure, the predicted border of the carbon formation region and the carbon-free region. The curves indicate the contour of 0.001 moles of carbon. The co-electrolysis region is delimited by the dashed line, cf. Fig. 2 . where $\mu$ is the chemical potential, $z$ stands for the charge number, $F$ denotes Faraday's constant, and $\varphi$ is the electric potential. Comparing the vanishing electrochemical affinity of reaction (10) and the electrochemical affinity of the reaction in the oxygen electrode

$$
\mathrm{O}^{2-} \rightleftharpoons \frac{1}{2} \mathrm{O}_{2}+2 \mathrm{e}^{-} \text {at anode }
$$

gives the difference between the electrochemical potential of electrons in the fuel electrode and the oxygen electrode, i.e. the open circuit potential. The values of the oxide ion electrochemical potential in the respective electrode cancel each other out, because the value of the potential is uniform due to the assumed equilibrium conditions, see ref. 33-35. The open circuit potential value does not depend on the fuel electrode electrochemical reaction used for the computation. This means that reaction (9) would yield the very same values of the open circuit potential, due to the uniqueness of the thermodynamic equilibrium.

$$
\begin{aligned}
& \Delta E_{\mathrm{OCP}}=\frac{1}{2 F}\left(\mu_{\mathrm{H}_{2} \mathrm{O}}-\mu_{\mathrm{H}_{2}}-\frac{1}{2} \mu_{\mathrm{O}_{2}}\right), \\
& =\frac{1}{2 F}\left(\mu_{\mathrm{H}_{2} \mathrm{O}}^{\mathrm{st}}-\mu_{\mathrm{H}_{2}}^{\mathrm{st}}-\frac{1}{2} \mu_{\mathrm{O}_{2}}^{\mathrm{st}}+R T \log \left(\frac{p_{\mathrm{H}_{2} \mathrm{O}}}{p_{\mathrm{H}_{2}}}\left(\frac{p^{\mathrm{st}}}{p_{\mathrm{O}_{2}}}\right)^{\frac{1}{2}}\right)\right) .
\end{aligned}
$$

In eqn (18), the symbol $\mu_{\mathrm{O}_{2}}$ denotes the chemical potential of oxygen at the anode, whereas $\mu_{\mathrm{H}_{2}}$ and $\mu_{\mathrm{H}_{2} \mathrm{O}}$ stand for the chemical potential of hydrogen and water vapor in the cathode, respectively. The assumed ideal gas approximation, see eqn (13), is used to derive eqn (19). The open circuit potential plots are shown in Fig. 8 for temperatures $600{ }^{\circ} \mathrm{C}, 800^{\circ} \mathrm{C}$ and $1000^{\circ} \mathrm{C}$, and pressures $1 \mathrm{bar}$ and $50 \mathrm{bar}$. Temperature dependence in the range studied is similar to that observed in the case of hydrogen 


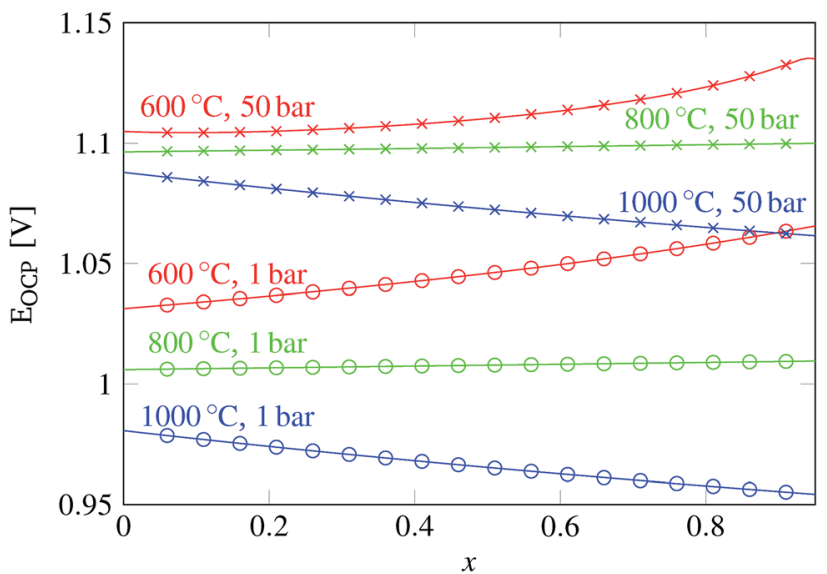

Fig. 8 Plot of the open circuit potential computed according to eqn (19) for the gas mixture with an initial composition $x \mathrm{CO}_{2}+(1-x) \mathrm{H}_{2} \mathrm{O}$ $+0.05 \mathrm{H}_{2}$ and $0.21 \mathrm{O}_{2}+0.79 \mathrm{~N}_{2}$ at the oxygen electrode. The value of the pressure at the oxygen counter-electrode is assumed to be the same as the total pressure in the fuel electrode.

fuel cells: the lower the temperature, the higher the OCP due to the increasing Gibbs free energy of the water vapor formation. Increasing the total pressure leads to an increase in OCP, and hence the partial pressure of oxygen in eqn (19) has a higher impact than the change in composition. The temperature dependence is altered by high pressure as well. As shown in Fig. 8 the OCP depends on the initial composition of the gaseous mixture in the cathode. Hence the OCP could be lowered by selecting a specific composition of the inlet gas at high temperatures.

\section{Conclusion}

The presented model aims to describe the behavior of gases and carbon in the cathode of a solid oxide co-electrolysis cell close to and in equilibrium.

The obtained results are relevant to all parts of the SOEC/ SOFC where the conditions allow the chemical equilibrium to be reached. This is the case whenever the composition of the mixture changes mainly due to the assumed reactions and effects of the other phenomena, for example, in the case that electron-transfer reactions and diffusion are negligible. This may hold true, for instance at the cell/stack entrance and outlet, but also locally inside the pores of the electrode where the electron-transfer reaction is, for some reason, limited.

For the sake of simplicity and due to lack of experimental data, the model takes into account the ideal behavior of the gaseous species and their mutual interactions. Only the graphite form of carbon was considered as a solid component in the cathode. The different types of solid carbon appearing in the SOCc fuel electrode were neglected due to the lack of reliable experimental data, see ref. 20 . The key advantage of the model is the chemical reaction mechanism adopted which permits all stoichiometric chemical reactions to be taken into account. A comprehensive comparison of the model prediction with the experimental data is difficult due to the magnitude of possible $\mathrm{C}: \mathrm{H}: \mathrm{O}$ ratios and their realization with different compounds.

The predicted carbon formation at ambient pressure is in agreement with the presented experimental results when the assumed gaseous mixture falls in the carbon deposition region given by the line connecting pure hydrogen and carbon monoxide in the ternary diagram, with the exception of pure carbon monoxide itself. The predicted carbon formation deviates at high pressures from the line connecting $\mathrm{CO}$ and $\mathrm{H}_{2}$ at a low $\mathrm{C} / \mathrm{H}$ ratio.

The absence of the solid carbon phase is, as expected, evident if the $\mathrm{C}: \mathrm{H}: \mathrm{O}$ mixture ratio falls behind the line of stoichiometric oxidation of carbon and hydrogen, the line connecting water vapor and carbon dioxide. Here the model failed to predict the observed carbon formation, see the points $t_{2}$ and $t_{3}$ indicated in Fig. 7. The model prediction of methane equilibrium behavior within the above-mentioned region shows a fair agreement with the experimental results. Thus a significant, direct, methane formation inside the SOC cell is possible either at significantly elevated pressure or at a low temperature.

The discrepancies between the model prediction and the kinetic experiment may have occurred due to insufficient relaxation to equilibrium. This also includes kinetic limitations and gas transport limitations.

The developed model is principally in good agreement with the available experimental data and therefore represents a foundation for the subsequent step to be undertaken, i.e. evaluation of the cathodic reaction kinetics on the basis of kinetic experiments.

\section{Conflicts of interest}

There are no conflicts to declare.

\section{Acknowledgements}

This project received funding from the Fuel Cells and Hydrogen 2 Joint Undertaking under grant agreement No. 671481. This Joint Undertaking receives support from the European Union's Horizon 2020 research and innovation programme, Hydrogen Europe and Hydrogen Europe research. PV gratefully acknowledges partial support through grant SVV-2017-260455.

\section{Notes and references}

1 B. Steele and A. Heinzel, Nature, 2001, 414, 345-352.

2 A. B. Stambouli and E. Traversa, Renewable Sustainable Energy Rev., 2002, 6, 433-455.

$3 \mathrm{~J} . \quad$ T. S. Irvine, D. Neagu, M. C. Verbraeken, C. Chatzichristodoulou, C. Graves and M. B. Mogensen, Nat. Energy, 2016, 1, 15014.

4 M. P. Carpanese, D. Clematis, A. Bertei, A. Giuliano, A. Sanson, E. Mercadelli, C. Nicolella and A. Barbucci, Solid State Ionics, 2017, 301, 106-115.

5 A. Bertei, M. Carpanese, D. Clematis, A. Barbucci, M. Bazant and C. Nicolella, Solid State Ionics, 2017, 303, 181-190. 
6 S. Y. Gómez and D. Hotza, Renewable Sustainable Energy Rev., 2016, 62, 155-174.

7 Y. Zheng, J. Wang, B. Yu, W. Zhang, J. Chen, J. Qiao and J. Zhang, Chem. Soc. Rev., 2017, 46, 1427-1463.

8 C. Graves, S. D. Ebbesen and M. Mogensen, Solid State Ionics, 2011, 192, 398-403.

9 Y. Tao, S. D. Ebbesen and M. Mogensen, ECS Trans., 2013, 50, 139-151.

10 X. Sun, M. Chen, S. H. Jensen, S. D. Ebbesen, C. Graves and M. Mogensen, Int. J. Hydrogen Energy, 2012, 37, 17101-17110.

11 J. Rostrup-Nielsen and D. L. Trimm, J. Catal., 1977, 48, 155165.

12 S. R. de Groot and P. Mazur, Non-equilibrium Thermodynamics, Dover Publications, New York, 1984.

13 J. Waldram, The Theory of Thermodynamics, Cambridge University Press, 1985.

14 G. Broers and B. Treijtel, Adv. Energy Convers., 1965, 5, 365382.

15 K. Sasaki and Y. Teraoka, J. Electrochem. Soc., 2003, 150, A878-A884.

16 K. Sasaki and Y. Teraoka, J. Electrochem. Soc., 2003, 150, A885-A888.

17 S. Assabumrungrat, N. Laosiripojana, V. Pavarajarn, W. Sangtongkitcharoen, A. Tangjitmatee and P. Praserthdam, J. Power Sources, 2005, 139, 55-60.

18 C. H. Wendel, P. Kazempoor and R. J. Braun, J. Power Sources, 2016, 301, 93-104.

19 T. Devin, M. Schwager and W. Mérida, J. Power Sources, 2014, 269, 424-429.

20 D. Chen, R. Lødeng, A. Anundskås, O. Olsvik and A. Holmen, Chem. Eng. Sci., 2001, 56, 1371-1379.

21 Z. Jaworski, B. Zakrzewska and P. Pianko-Oprych, Rev. Chem. Eng., 2017, 33, 217-235.
22 M. W. Chase, NIST-JANAF Thermochemical Tables, Data reported in NIST standard reference database 69, June 2005 release: NIST Chemistry WebBook, J. Phys. Chem. Ref. Data, Monograph 9, 1998, pp. 1-1951.

23 NASA and CEA, NASA computer program for calculating of the Chemical Equilibrium with Applications, NASA Glenn Research Center, Cleveland, OH, 2015.

24 M. Torrell, S. García-Rodríguez, A. Morata, G. Penelas and A. Tarancón, Faraday Discuss., 2015, 182, 241-255.

25 Y. Shi, Y. Luo, N. Cai, J. Qian, S. Wang, W. Li and H. Wang, Electrochim. Acta, 2013, 88, 644-653.

26 T. Takeguchi, Y. Kani, T. Yano, R. Kikuchi, K. Eguchi, K. Tsujimoto, Y. Uchida, A. Ueno, K. Omoshiki and M. Aizawa, J. Power Sources, 2002, 112, 588-595.

27 V. Alzate-Restrepo and J. M. Hill, J. Power Sources, 2010, 195, 1344-1351.

28 L. Z. Bian, Z. Y. Chen, L. J. Wang, F. S. Li and K. C. Chou, Int. J. Hydrogen Energy, 2017, 42, 14246-14252.

29 C. M. Finnerty, N. J. Coe, R. H. Cunningham and R. M. Ormerod, Catal. Today, 1998, 46, 137-145.

30 J. Kuhn and O. Kesler, J. Power Sources, 2014, 246, 430-437.

31 W. Li, H. Wang, Y. Shi and N. Cai, Int. J. Hydrogen Energy, 2013, 38, 11104-11109.

32 L. Kleiminger, T. Li, K. Li and G. Kelsall, Electrochim. Acta, 2015, 179, 565-577.

33 M. Pavelka and F. Maršík, Int. J. Hydrogen Energy, 2013, 38, 7102-7113.

34 M. Pavelka, F. Wandschneider and P. Mazur, J. Power Sources, 2015, 293, 400-408.

35 P. Vágner, M. Pavelka and F. Maršík, J. Non-Equilib. Thermodyn., 2017, 42, 201-216. 